\title{
Environmental values in the petrochemical industry: A Q-method study in South
}

\section{West Iran}

\author{
Omid M. Ghoochani ${ }^{1}$, Azadeh Bakhshi ${ }^{1}$, Matthew Cotton ${ }^{2}$, Azar Hashemi Nejad ${ }^{1}$, \\ Mansour Ghanian ${ }^{1^{*}}$ \\ 1 Department of Agricultural Extension and Education, Ramin Agriculture and Natural Resources University of Khuzestan, Iran \\ 2 Department of Urban Studies and Planning, University of Sheffield, United Kingdom \\ E-mail address (*corresponding author): M_ghanian@yahoo.com
}

\begin{abstract}
Achieving sustainable development in different regional and cultural contexts is dependent, in part, upon an understanding of key actors' underlying environmental, social and economic values. The social research technique called Q-methodology presents an effective means to explore such values as a matter of discourse: revealing the typologies of stakeholder perspectives within a given debate. Q-method involves factor analysis of participant rank-ordered preselected statements on a topic. The resultant factors are then reinterpreted as social discourses. In this study we use Q-methodology to explore the environmental values of Health Safety and Environmental (HSE) managers in petrochemical companies in Khuzestan province in southwest Iran. Khuzestan is a key region of petrochemical product development, with significant associated environmental pollution effects. Understanding HSE managers' attitudes to environmental protection is of value in predicting broader environmental impacts to the region, given the relative importance of their role in regulating the environmental performance of this industry. Our results reveal four distinct and varied perspectives on environmental protection labelled: 'Environmental stewardship', 'Environmental presentism', 'Technological optimism' and 'Enlightened anthropocentrism'. We then discuss how these four emergent perspectives correspond to broader environmental discourses as categorized by John Dryzek: i.e. green rationalism, economic rationalism, prometheanism and ecological modernization respectively.
\end{abstract}

KEY WORDS: environmental values, petrochemicals, Q-methodology, sustainable development, Iran

\subsection{Introduction - environmental perceptions and environmental values}

There is increasing awareness within international policy networks of the anthropogenic environmental impacts resulting from the improper and uncontrolled use of natural resources. The twin factors of increasing economic activity and population growth in economically developing countries is often associated with increasing energy and consumption demand (ATIQUL HAQ ET AL., 2010), frequently leading to accelerated environmental degradation despite improved technological efficiencies in resource use (IIZUKA, 2000). Associated impacts include (among others) water scarcity, air, soil, noise and light pollution, global climate change, ozone depletion, deforestation, ocean acidification and hazardous waste disposal; each posing dangerous threats to current and future human and nonhuman life and wellbeing (MISHRA \& SHUKLA, 2013; OSBALDisTon \& SCHOTT, 2012; STERN, 2000, DEL ANGEL-PEREZ \& VillagomeZ-CoRTES, 2014; DAvies \& Hodge, 2007; ZAND Hessami \& YouseFI, 2013; BARBER ET AL., 2009).

One significant component of tackling the complexity of these environmental problems is to understand the underlying environmental values held by social actors with responsibilities for environmental protection, and the relationship between underlying environmental values and pro-environmental behaviors and social practices 
(ANDERSON, 2012; POORTINGA ET AL., 2004; OSBALDISTON \& SCHOTT, 2012). This issue has remained a complex and contentious aspect of environmental social science for over forty years (Kollmuss \& AGEYMAN, 2002). It is a matter made yet more complex by taking into account national, regional and organizational cultural influences upon environmental values and their attendant effects upon the social construction of environmental problems; and the range of acceptable solutions to policy-makers and other key actors involved in environmental management. In particular, the twin tasks of addressing natural resource constraints and ameliorating environmental degradation are becoming core managerial decisions for a range of public and private sector organizations (HECKBERT ET AL., 2010; CostanZA, 1989; GUTIERREZ, 2006). Natural resources such as food, wood, fiber, minerals, and energy resources, alongside the ecosystem services that provide water and air purification, are increasingly recognized as foundational to economic growth and human wellbeing (GUTIERREZ, 2006); particularly in developing countries where such resources and services are central to income generation and the meeting of daily needs (cited in HUNTER \& STRIFE, 2010).

The empirical study of underlying values and their effects upon organizational environmental performance have been an important cornerstone of environmental social science. In social psychological terms, environmental values are linked to perceptions: the subjective ways in which individuals experience and evaluate their surroundings (WARF, 2006; HAQ \& VANWING, 2010; RAMALHO-GUEDES \& LUIZE-Do-CARMO, 2013). However, such perceptions are interwoven into complex patterns of personal experiences, moral and aesthetic values, attitudes, interests, habits, motives, social learning practices and personality traits - all of which have a bearing upon the formation of such environmental perceptions (INAGAMI \& OHNO, 2009; BEDROUS, 2010). Sociologists and philosophers have explored environmental values and human-natural environment relationships in diverse ways: coloured either by anthropocentric world views which place overwhelming emphasis on the value of natural systems for economic growth (WILLIAMS, 2007; CHen ET AL., 2012; LAUBER \& TIDBALL, 2014) with an underlying ethos of human exemptionalism; or conversely focusing upon the intrinsic value of nature (O'NEILL, 1992), or connection of an individual 'self' within a broader ecological 'Self' (NAESS, 1973). The latter has been empirically explored through HINES ET AL.'S (1987) classification of environmental attitudes in relation to holistic ecological values and attitudes towards taking pro-environmental actions.

To complicate matters further, environmental values evolve in concert with economic and social development practices, and the analysis of such values particularly in economically developing nations is becoming of increasing concern to academic social scientists and environmental policy makers (INAGAMI \& OHNO, 2009). This is because environmental degradation arising from natural resource exploitation and utilization can threaten regional sustainable development by exacerbating poverty, malnutrition and other health inequalities (the so-called 'resource curse'). It therefore behoves governmental and nongovernmental actors to better understand stakeholder awareness of and attitudes towards the underlying nature of water, air and ground point and non-point source pollution in regions affected by environmental degradation (ANDERSON ET AL., 2007; EUCHARIA ET AL., 2012). Understanding complex and contested environmental values in ecologically stressed regions is also inherently a matter of environmental justice (HOFRICHTER, 1993; SCHLOSBERG, 2007). However, acting upon such values to achieve environmentally sustainable outcomes remains fraught with contradictions. Achieving sustainable development is a process derived from science, but it requires legitimacy from identifying environmental 'biospheric imperatives', whilst emphasizing economic development alongside cultural diversity and socially constructed and often ambiguous objectives (REDCLIFT, 1993). However, understanding and delineating the environmental values held by key actors in specific organizational and cultural contexts is an important aspect of understanding how sustainable development manifests as a discourse of the environment (DRYZEK, 1997), and can provide key insights into pro-environmental social practices.

\subsection{Environmental perceptions and sustainable development in Iran}

This empirical study centers upon environmental values in Iran. Iran has diverse climatic and environmental conditions (NCCO1, 2010), however, more than $82 \%$ of Iranian territory is located in the arid and semi-arid zones of the world (NCCO, 2003). These regions are particularly vulnerable to the long-term impacts of anthropogenic climate change. Complex environmental diversity

${ }^{1}$ Iran National Climate Change Office 
can be seen in southwest Iran in the Khuzestan province - an area rich in natural resources that provides high value food and export income for the country. Khuzestan remains one of the most industrialized provinces of the country. Iran holds the fourth largest crude oil reserves in the world (HosSEINI ET AL., 2013) and much of the resource is concentrated in Khuzestan Province, with petrochemical industries dominating the economic development of the region. Petrochemical industries principally concentrate in and around Mahshahr city. Though crucial to economic development, oil and petroleum products produced in the region, like in other petrochemical focused regional economies, cause significant pollution. Of particular note is the contamination of rivers, aquifers and other groundwater sources (BEHNOOD ET AL., 2013), with further undeniable environmental impacts on biodiversity, global climate change, drought and public health (SMITH, 1993; UTZINGER, 2005). Attending to public health, safety and environmental conservation is a crucial subject in Iran's developmental program. However, much work at the level of petrochemical industry organizations has been limited to environmental information campaigns to increase and update employees' knowledge, often with limited success.

In this study we focus specifically upon gaining a better understanding of the environmental values of 'middle managers' within petrochemical organizations with environmental responsibilities, namely the Health, Safety and Environmental Managers (HSE). Focus on their roles is important due to their position of influence upon the organizational cultures of pro-environmental social practices amongst employees. For instance, they may influence engineers to design and subsequently manufacture products in more or less environmentally benign ways, or else may use or otherwise ignore environmental criteria in their decisions. In general, managerial environmental values are of increasing academic concern, as consumers demand ever greater levels of corporate social responsibility (DIBRELL ET AL., 2011); yet managers often have limited knowledge of, and care for, environmental concerns (CHENDO, 2013), sometimes resulting in local to international-scale disagreements (ARMATAS ET AL., 2014). The values of HSE managers in petrochemical industries can have considerable influence, therefore, upon the scale and intensity of environmental impacts experienced regionally, and in Iran and its surrounding countries, more broadly. This is because the values of such managers are key socio-cultural drivers of managerial environmental decisions within petrochemical industries, and this has a direct influence upon the environmental quality of the region as a whole. In addition, our empirical work with this subgroup of managers can simultaneously contribute to broader understandings of organizational environmental values in other sectoral, regional and governance contexts.

\subsection{Methodology}

Understanding complex environmental values necessarily involves multi-method and innovative approaches (WEEKS, 2008; DASGUPTA \& VIRA, 2005). Q-methodology has gained recent popularity as a means to analyze complex environmental values (BARRY \& PROOPS, 1999; STERGIOU \& Airey, 2010; COTTON \& DEVINE-WRIGHT, 2011). Q-methodology, from the work of physicist-turned-psychologist William Stephenson (STEPHENSON, 1953) offers a potential means to bridge qualitative and quantitative research traditions by combining factor analysis of respondents' rank ordering of statements about a topic, combined with interpretation of the resultant factor array as 'discourses' or 'idealized accounts' (BROWN, 1993; AL-BUSAIDI, 2008; BAKER ET AL., 2010; DAVIS \& MiChELLE, 2011). The application of Q-methodology is particularly well suited to this type of study, as it provides an opportunity to explore areas of discursive consensus and divergence in underlying environmental values - thus providing information on areas of agreement and conflict in contentious environmental management debates (STEELMAN \& MAGUIRE, 1999). What is interesting and valuable about Q-method is its capacity to link micro-discourses, in the sense of concerning shared conceptualizations, language use and communicative practices (FAIRCLOUGH, 2003; VAN DIJK, 2001), with the broader macro-level discourses (see COTTON, 2015): heterogeneous and shared ways of apprehending the natural world which inherently draw out contestation for capturing the terms of environmental policy-making (DRYZEK, 1997). It is Dryzek's typologies of shared environmental discourses (1) problem-solving, 2) survivalism, 3) sustainability, and 4) green radicalism) that will be returned to in the analysis of the emergent environmental values in the results section.

Q-method has been used in a growing range of environmental management case studies concerning issues such as climate change (HALL \& WREFORD, 2012), energy technologies (COTTON \& DEVINEWRIGHT, 2011; ELLIS ET AL., 2007; VENABLES ET AL., 2009) and forestry management (STEELMAN \& MAGUIRE, 1999; DASGUPTA \& VIRA, 2005); or else more generally around environmental attitudes 
and sustainable development discourses in different sectors or at different political scales (ADDAMS \& Proops, 2000; ATIQUl HAQ ET AL., 2010; CoTTON \& MAHROOS-AlSAIARI, 2014; CURRY ET AL., 2012; FRANZI ET AL. 2009; KINCAID, 2011). The benefit of Q-methodology lies in its capacity to identify relative priorities across a range of influences in the minds of respondents through Gestalt inquiry into human subjectivity (LOGO, 2013), thus giving a fuller portrait of their concerns when achievement of all goals is impossible (Davies \& Hodge, 2007). Moreover, it provides a valuable means to demonstrate the nature of the mental frameworks of actors in a particular context enabling one to formulate some important questions regarding the motivations of managers in the context of a rapidly changing policy landscape (ibid.).

\subsection{Q-method in practice}

Q-method systematically evaluates subjective social perspectives by rendering them open to statistical analysis in order to extract a series of 'idealized accounts' or 'discourses'. Q-method researchers use statistical methods to objectively identify shared subjective positions (MATINGA ET AL., 2014; DAVIS \& Michelle, 2011; BAKER ET AL., 2006; Robbins \& KRUEger, 2000; Kristensen \& ENEVOLDSEN, 2008). Respondents' categorizations are 'emergent' in the sense that they arise from inductive self-sorting of a range of statements, rather than being deduced from preconceived categories in the manner of a social survey (referred to as R-method). Furthermore, Rmethod often renders minority voices as outliers, whereas all respondents' positions have equal relevance in Q-method (MATINGA ET AL., 2014; WINT, 2013). The aim is to combine qualitative and quantitative research characteristics by exploring and identifying a number of discourses of people concerning a specific theme (DAVIS \& Michelle, 2011; VAN EXEL \& DE GRAAF, 2005). As such, it is primarily an inductive method, rather than a means to prove hypotheses, whilst bringing a sense of coherence to research questions that have many potentially complex and socially contested answers (LoGO, 2013).

Q-method has five common steps (from ARMATAS ET AL., 2014):

1. Creation of the concourse and Q-set;

2. Recruitment of Q-sort participants (P-set);

3. Completion of the Q-sort;

4. Data analysis; and

5. Factor interpretation
The concourse is an extensive collection of items or statements related to the research topic, which is sampled to form a smaller Q-set that participants will rank order (a process termed a Q-sort procedure). The methods used to develop the concourse and Q-set can involve primary qualitative data collection from focus groups and interviews (for example) and/or secondary sources such as academic and policy literatures, social and print media and other forms of written documentation. It is important in the selection of documents from which statements are retrieved, to take local context into account and ensure representation of a broad range of sentiments regarding the topic of interest (ARMATAS ET AL., 2014). In this study, 6 face-to-face semistructured interviews were conducted with a range of stakeholders during the period from April to May 2014. The interviews were recorded and transcribed, with thematic elements drawn out to form statements for the concourse. These were supplemented through a review and sampling of related secondary literature. Thus, a quasi-naturalistic sampling approach was used to produce and to select a set of statements as the Q-population or the concourse of this study.

The generated population of statements was examined for relevance, intelligibility and similarity to other statements, then duplications were removed. After correcting redundant and unclear statements, 154 statements were sampled from the total collected statements to constitute the final Q-population. Then, a group of experts including the researchers examined the statements to prioritize and simplify them with regard to environmental issues. Users of Q-methodology should always ensure that the statements address the full spectrum of subject areas evident within the concourse (ForouZANI ET Al., 2013). Finally, 16 statements out of a total 154 were selected to form the Q-sample. Each statement was printed on a separate card for Q-sorting (the Q-sample can be seen in Table 3) and numbered. Participants (the P-set) were recruited through strategic sampling (in the manner of a qualitative study) rather than random sampling (in the manner of a social survey). The aim is to ensure 'comprehensiveness and diversity, rather than representativeness or quantity'. This is because Q-methodology is 'intended to identify subjectivities that exist, not to determine how those subjectivities are distributed across a population' (from ARMATAS ET AL., 2014). The P-set focused upon recruiting each HSE manager from each of the petrochemical companies in the Khuzestan region. 
Each participant then rank ordered the statements from the Q-set. They then placed each individual numbered statement onto the Q-board, which provides the framework for the Q-sorting process. Q-boards typically (but not always) require participants to distribute the cards in a manner similar to a quasi-normal distribution (FRANTZI ET AL., 2009; ARMATAS ET AL., 2014) in order to ensure that participants utilize the full range of rating positions, as illustrated in Table 1.

Table 1. Q-sort ranking used for assessing statement scores

\begin{tabular}{|c|c|c|c|c|c|c|}
\hline $\begin{array}{r}\text { Mos } \\
\text { unimpor }\end{array}$ & & & & & & $\begin{array}{c}\text { Most } \\
\text { important }\end{array}$ \\
\hline \multirow[t]{4}{*}{-3} & -2 & -1 & 0 & +1 & +2 & +3 \\
\hline & -2 & -1 & 0 & +1 & +2 & \\
\hline & & -1 & 0 & +1 & & \\
\hline & & & 0 & & & \\
\hline
\end{tabular}

The completed Q-sorts are subsequently subjected to factor analysis. As a result of its statistical nature and unique data collection process, Q-methodology is amenable to 'objective analysis' and minimizes the intrusion of researcher bias. The analysis of the Q-sorts is a purely technical, objective procedure. People with similar views on the topic will tend to share the same factor. A factor loading is determined for each Q-sort, expressing the extent to which each Q-sort is associated with each factor. The number of factors in the final set depends on the variability in the elicited Q-sorts. In this study the software package SPSS was used to carry out the statistical analysis.

\subsection{Results}

The ranked statements in each HSE manager's Q-sort formed the basic unit of data for analysis. The initial stage of the analysis was the construction of a correlation matrix of all the sorts. The matrix is then factor analyzed, using
Principal Components Analysis (PCA). In this process the correlation matrix was examined to determine how many different families or groups (factors) existed. Hence the purpose of factor analysis was to determine if there was a smaller number of Q-sorts that constituted patterns of discourse among the participants. After conducting PCA an initial set of 'factor loadings' were derived for each of the Q-sorts. The loadings showed the extent to which each Q-sort was associated with each factor. The factors are then orthogonally rotated (using in this case Varimax rotation) to 'find the simplest structure in the data that can explain the greatest amount of variability' (SWEDEEN, 2006). In this study a four factor solution was retained, with each factor having an Eigenvalue $>1.00$, and at least two participants loading on that factor. Each factor represents a distinct and aggregated viewpoint that emphasizes different responsibilities and expectations. Eigenvalues and percentage variance explained by each factor are shown in Table 2 .

Table 2. Eigenvalues and variance explained

\begin{tabular}{|l|c|c|c|c|c|}
\hline & Factor 1 & Factor 2 & Factor 3 & Factor 4 & Total \\
\hline Eigenvalues & 4.99 & 2.14 & 2.12 & 1.17 & 86.97 \\
\hline \% explanation of variance & 41.64 & 17.85 & 17.66 & 9.80 & \\
\hline
\end{tabular}

\subsection{Discussion}

As can be seen in Table 2 the four factors combined explain $86.97 \%$ of variance. To interpret these four factors, factor scores were used. For convenience, the statements were returned to the original Q-sort format, such that the two statements with the highest weighted composites were assigned +3 , the next four highest assigned +2 and so on. As noted above, analysis of the Q-sorts revealed four factors and the converted factor scores were then used to interpret how the statements were ranked both within and between factors. In each case, the factor is given a label that succinctly summarizes its broader meaning. The factor scores identified which statements had 
some degree of common ranking across factors, and which ones had a high degree of disagreement between factors. Differences of two or more between factor scores can be considered significant (BROWN, 1993). The 16 statements with their factor scores are shown in Table 3. By summarizing the factor scores and then reinterpreting the statements that load on that factor, the qualitative analysis reveals an array of distinct social discourses. In our analysis our qualitative interpretation of the factors links the Q-sorters' underlying values to a range of broader environmental macro-discourses (we use DRYZEK's, 1997) typologies of environmental discourse throughout to guide the discussion).

Table 3. Factor Q-sort values and each statement

\begin{tabular}{|c|c|c|c|c|}
\hline Statements & 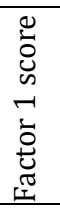 & 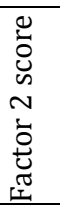 & 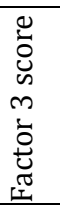 & 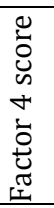 \\
\hline $\begin{array}{l}\text { 1. The balance of nature is very fragile and shouldn't be compromised in favor of human } \\
\text { welfare. }\end{array}$ & 0 & -1 & 0 & 0 \\
\hline $\begin{array}{l}\text { 2. If the damage to the environment can be compensated for financially, then nature can be } \\
\text { used as you please. }\end{array}$ & 0 & 0 & 0 & -1 \\
\hline $\begin{array}{l}\text { 3. Solving the economic problems of the present is more important than dealing with the } \\
\text { protection of the future environment. }\end{array}$ & -1 & +2 & +1 & +2 \\
\hline 4. Humankind has the right to harm the natural environment in order to obtain their needs. & -3 & +1 & -2 & 0 \\
\hline 5. The present generation's welfare should not be sacrificed for the next generation's needs. & +1 & +3 & -2 & +1 \\
\hline $\begin{array}{l}\text { 6. Industrial activities in the vicinity of, and around, the city are causing irreversible damage } \\
\text { to the urban environment. }\end{array}$ & +2 & -2 & 0 & -1 \\
\hline $\begin{array}{l}\text { 7. Based on current development I expect that environmental conditions will be better in } \\
\text { the future. }\end{array}$ & -2 & +1 & +1 & -2 \\
\hline $\begin{array}{l}\text { 8. I think that economic growth and environmental improvement can be provided } \\
\text { simultaneously. }\end{array}$ & +1 & 0 & -1 & +3 \\
\hline 9. I think that humans exploit nature. & 0 & 0 & -1 & -2 \\
\hline $\begin{array}{l}\text { 10. I think that we should prioritize alternative low-carbon energy resources such as wind } \\
\text { and solar energy, as they are more compatible with environmental sustainability. }\end{array}$ & +3 & 0 & -1 & -1 \\
\hline $\begin{array}{l}\text { 11. The value of the environment doesn't depend on human use, it is valuable in and of } \\
\text { itself. }\end{array}$ & +2 & -1 & +2 & +2 \\
\hline $\begin{array}{l}\text { 12. Humankind does not have to adapt with the environment, since the environment can be } \\
\text { reconstructed to meet his needs. }\end{array}$ & -2 & -1 & +3 & +1 \\
\hline $\begin{array}{l}\text { 13. I think that commonly used methods of agriculture are leading to significant } \\
\text { environmental degradation. }\end{array}$ & +1 & +1 & +1 & -3 \\
\hline $\begin{array}{l}\text { 14. I think that the present industrial development of the region will not lead to increased } \\
\text { environmental pollution. }\end{array}$ & 0 & +2 & +2 & 0 \\
\hline 15. A lack of fines and penalties lead to pollution of the environment. & -1 & -2 & 0 & 0 \\
\hline $\begin{array}{l}\text { 16. More than government agencies, non-Governmental organizations preserve } \\
\text { environmental interests. }\end{array}$ & -1 & -3 & -3 & +1 \\
\hline
\end{tabular}

\section{Factor 1: Environmental stewardship}

This discourse is indicative of a pro-low carbon transition discourse expressed in terms of support for alternative energy resources such as wind and solar energy as a means to achieve long term futurity and environmental sustainability (statement 10: +3 ). This links to environmental values that emphasize the intrinsic value of nature (statement 11: +2 ), and a concomitant concern that the instrumental, anthropocentric valuing of nature prioritizes nature as a resource 
for human use (statement 4: -3) resulting in irreversible damage to the urban environment of the region (statement 6: +2 ). Due to current human activities, proponents of this perspective express pessimism over a long-term weakening of environmental conditions (statement 7: -2); whilst simultaneously refusing to technologically alter nature in order to provide for human needs (statement 4: -3). In essence, this factor is representative of a deeper underlying discourse of green rationalism - whereby the main focus is upon achieving long-term environmental futurity through (in particular) sustainable energy, and a concern for a reformation of environmental valuation away from anthropocentric, promethean, techno-centric and economic means.

\section{Factor 2: Environmental presentism}

This discourse expresses how the present generation's welfare should not be constrained because of the next generation's needs (statement 6: +3 ). Similarly there is a desire for solving the economic problems of the present rather than protecting the future environment (statement 4: +1), whilst asserting that the present industrial situation will not lead to further (increasing) problems of environmental pollution (statement 7: +1 ). Proponents of this discourse do not fundamentally believe that the balance of nature is fragile (statement 1: -1). As such, there are no hard limits placed on human activities. The underlying discourse, using the DRYZEK (1997) typology, is thus one of economic rationalism: that there are no absolute limits to environmental systems (in a manner espoused by the survivalists represented by the Club of Rome), and that current and future economic progress and robust support for modern industry is inherently desirable.

\section{Factor 3: Technological optimism}

This discourse is characterized by a belief that humanity can create the environment it desires, and does not place restrictive limits onto human activities (statement 12: +3 ). Although this factor acknowledges the inherent or intrinsic value of nature (statement 11: +2 ), there is less concern about current industrial activities causing environmental pollution (statement 14: +2 ). In this factor, human kind should not harm the natural environment in order to meet present needs or requirements (Statement 4: -2 ), and emphasizes that more attention should be paid to the next generation's needs (Statement 5: -2) whilst showing concern that economic growth and environmental improvement cannot be provided simultaneously (Statement 8: -1). Advocates also do not believe that NGOs are adequate protectors of environmental benefits when compared to Governmental organizations (Statement 16: -3). Such a discourse is representative of the promethean typology emphasizing a lack of hard limits within environmental systems, whilst maintaining a concern for environmental protection over the longer term. What is important to note about this factor is the emphasis on the capacity of humankind to protect the future environment through technological development. Conversely, this factor expresses the position that economic (marketbased) or civil society organizational means for environmental protection alone are inadequate.

\section{Factor 4: Enlightened anthropocentrism}

This discourse reveals a perspective that the goals of improving economic activity and improving the environment do not conflict with one another (statement 8: +3 ), whilst simultaneously recognizing that humans do exploit the natural environment (statement 9: -2). This viewpoint pays more attention to the role of environmental NGOs in acting toward preservation of the environment (statement 16: +1). This viewpoint clearly espouses an ethos of inherent or intrinsic valuation of ecological systems (statement 11: +2 ); though simultaneously believes in economic growth as an important facet of sustainable development (statement 3: +2 ). Interestingly, this viewpoint does not express concern for conventional agricultural activities as a cause of environmental degradation (statement 13: -3), nor is renewable energy prioritized (statement 10: -1). To summarize, this discourse is indicative of the ecological modernization typology, in the sense of a type of enlightened anthropocentrism, asserting that economic development can be concurrent with environmental adaptation, whilst maintaining a concern for long-term environmental protection, except when it conflicts with short-term economic need.

\subsection{Conclusion}

Q-method provides an inductive approach to define and delineate stake holder positions within controversial debates, identifying here how key HSE manager stakeholders conceptualize environmental management within the petrochemicals sector. Q-method identifies latent discourses, revealing a more nuanced picture of competing perspectives than those traditionally presumed by policymakers, 
or organizational managers (BARRY \& PROOPS, 1999; COTTON, 2015). The application of Q-method in this study revealed four distinct discourses among the HSE's managers of petrochemical companies in southwest Iran. The identified discourses were described in terms of Environmental stewardship, Environmental Presentism, Technological Optimism, and Ecological Modernization. The emergent discourses reveal areas of non-consensus among the HSE's managers of petrochemical companies. The differences in factor scores reveal differences in the underlying value frameworks exposed i.e. in subjective differences in how different managers conceive of, and communicate, their point of view about an environmental subject (ZABALA, 2014).

Q-methodology structures the complexity of participants' viewpoints to a few manageable themes, indicative of broader environmental discourses, i.e. shared ways of perceiving and valuing the environment (DRYZEK, 1997). The first discourse prioritizes the protection of human health and the natural environment, by an evolving sense of environmental responsibility or stewardship in the manner of the green rationalist - concerned with a radical restructuring of the petrochemicals sector away from the dominant ideological structures of promethean, anthropocentric and economic discourses that dominate the industry. It is interesting to note that this factor correlates strongly with the perspective of the middle managers of the largest petroleum companies, and the importance of this discourse is illustrated by that fact that these individuals' actions will likely be the most affective on the quality of the regional environment. Environmental presentism emerges most strongly in the second discourse, however, such presentism is significantly associated with poor working conditions, ineffective management/leadership, and work/life imbalance (MUSICH ET AL., 2006). The emphasis is upon economic rationalism that prioritizes marketbased values and short-term profit over longterm environmental protection: in essence a form of environmental skepticism (see LOMBERG, 2003). By contrast the technological optimism or prometheanism of the third discourse is inherently tied to ideas of progress and modernity, which play a powerful role in sustaining the prevalent mode of capitalist production in the face of its environmental harm (KEARY, no date). With little concern over environmental limits and trust in techno-fixes to environmental problems, this discourse presents an alternative to the market and civil-society based solutions to environmental management problems. Finally, the fourth discourse is indicative of ecological modernization: the centripetal movement of ecological interests, ideas and considerations in social practices and institutional developments (cited in MoL, 2002). In this last discourse, economic development is posited to work in concert with environmental interests and considerations, whilst his empirical research shows that the former is prioritized over the latter in this case.

Collectively, these discourses represent fundamental conflicts among the viewpoints of HSE's managers over how their industry should treat environment protection. This Q-method study dispels the assumption that HSE managers think and act with a homogeneous set of underlying environmental values despite their similarity in role and industrial context. The competing rationalities and underlying environmental discourses revealed through this study highlight the complex and contested nature of the underlying environmental values espoused despite their seemingly homogeneous grouping within middle management. Given their key role in regional environmental protection in the most industrialized areas of Iran, the lack of consensus on key environmental, social, economic values represents fundamental conflicts in the characterization of sustainable development, its relative importance and the strategies for its implementation. The implications of this heterogeneity of values are that environmental futures, inter-organizational competition, corporate social responsibilities and environmental compliance are likely to differ widely, as environmental protection measures are interpreted differently through the worldviews of the managers responsible for them. It is, therefore, a matter for further research to examine the attendant variability in the effects of regional environmental quality and environmental justice emerging as a result.

\section{Acknowledgements:}

The authors would like to thank all these who participated in this study by completing the Q-sorts, or by providing in-depth interviews.

\section{References}

Atiqul Haq S.M., Vanwing T., Hens L. 2010. Perception, Environmental Degradation and Family Size Preference: a Context of Developing Countries. J. Sustain. Dev., 3 (4): 102-108.

Addams H., Proops J.L. (eds.) 2000. Social discourse and environmental policy: an application of $Q$ methodology. Edward Elgar Publishing, Cheltenham.

Anderson B.A., Romani J.H., Phillips H. Wentzel M., Tlabela K. 2007. Exploring environmental perceptions, behaviors 
and awareness: water and water pollution in South Africa. Population Environ., 28: 133-161.

Armatas C.A. Venn T.J., Watson V.E. 2014. Applying Qmethodology to select and define attributes for nonmarket valuation: A case study from Northwest Wyoming, United States. Ecol. Econ., 107: 447-456.

Barber N., Taylor C., Strick S. 2009. Wine consumers' environmental knowledge and attitudes: Influence on willingness to purchase. Int. J. Wine Res., 1. 59-72.

Barry J., Proops J. 1999. Seeking sustainability discourses with Q methodology. Ecol. Econ., 28(3): 337-345.

Bedrous A.V. 2010. Comparing Individual- and NationalLevel explanations of Environmental Attitudes. Sociology Theses, Dissertations \& Student Research. Paper 7. http://digitalcommons.unl.edu/sociologydiss/7.

Behnood R., Anvaripour B., Jaafarzade Haghighi Fard, N., Farasati M. 2013. Application of Natural Sorbents in Crude Oil Adsorption. Iranian J. Oil \& Gas Sci. Tech., 24: 01-11. http://ijogst.put.ac.ir.

Brown S.R. 1993. A primer on Q methodology. Operant subjectivity, 16 (3/4): 91-138.

Chen X., Peterson M.N., Hull V., Lu C., Lee G., Hong D., Liu J. 2011. Effects of attitudinal and socio-demographic factors on pro-environmental behavior in urban China. Environ. Cons., 1-8. Foundation for Environmental Conservation.

Chendo N.A. 2013. Managers' Perceptions of Environmental Sustainability in Small and Medium Scale Enterprises (SMEs): Implication for Competitive Marketing Advantages for Sachet Water Manufacturers in Anambra State, Nigeria. European J. Bus. Manage., 5 (7): 186-195.

Costanza R. 1989. What is Ecological Economics? Ecol. Econ., 1: $1-7$

Costanza R. 2001. Visions, Values, Valuation, and the Need for an Ecological Economics. BioScience, 51 (6): 459-468.

Cotton M., Devine-Wright P. 2011. Discourses of energy infrastructure development: a Q-method study of electricity transmission line siting in the UK. Environ. Plan.- A, 43 (4), 942.

Cotton M. 2015. Stakeholder perspectives on shale gas fracking: a Q-method study of environmental discourses. Environ. Plan.- A, 47 (9): 1944-1962.

Cotton M.D., Mahroos-Alsaiari A.A. 2015. Key actor perspectives on stakeholder engagement in Omani Environmental Impact Assessment: an application of Q-Methodology. J. Environ. Plan. Manage., 58 (1): 91-112.

Curry R., Barry J., McClenaghan A. 2013. Northern Visions? Applying Q methodology to understand stakeholder views on the environmental and resource dimensions of sustainability. J. Environ. Plan. Manage., 56 (5): 624-649.

Dasgupta P., Vira B. 2005. Q Methodology' for Mapping Stakeholder Perceptions In Participatory Forest Management. the UK Department for International Development (DFID) for the benefit of developing countries under its Natural Resources Systems Programme (project no R8280).

Davies B.B., Hodge I.D. 2007. Exploring environmental perspectives in lowland agriculture: A Q methodology study in East Anglia, UK. J. Ecol. Econ., 61: 323-333.

Del Angel-Perez A.L., Villagomez-Cortes J.A. 2014. Environment Perceptions and Conservation Preferences along the Coatepec-La Antigua Watershed, México. J. Human Ecol., 46 (3): 309-318.

Dibrell C., Craig J,B., Hansen E.N. 2011. How managerial attitudes toward the natural environment affect market orientation and innovation. J. Bus. Res., 64: 401-407.

Dryzek J. 1997. Politics of the Earth: Environmental Discourses. Oxford Univ. Press, Oxford.

Ellis G., Barry J., Robinson C. 2007. Many ways to say 'no', different ways to say 'yes': applying Q-methodology to understand public acceptance of wind farm proposals. J. Environ. Plan. Manage., 50 (4): 517-551.

Frantzi S., Carter N.T., Lovett J.C. 2009. Exploring discourses on international environmental regime effectiveness with Q methodology: A case study of the Mediterranean Action Plan. J. Environ. Plan. Manage., 90: 177-186

Ghimire D.J., Mohai P. 2005. Environmentalism and Contraceptive Use: How people in less developed settings approach environmental issues. Popul. Environ., 27, (1): 29-61.

Gowdy G., Erickson J.D. 2005. The approach of ecological economics. Cambridge J. Econ., 29: 207-222.

Gutierrez R.C. 2006. What is Ecological Economics? by Earth Econ.

Hall C., Wreford A. 2012. Adaptation to climate change: the attitudes of stakeholders in the livestock industry. Mitigation Adaptation Strategies Global Change, 17 (2): 207-222.

Haq S.M.A., Vanwing T. 2010. Perception, Environmental Degradation and Family Size Preference: a Context of Developing Countries. J. Sustain. Dev.., 3 (4): 102-108.

Heckbert S. Baynes T., Reeson A. 2010. Agent- based modeling ecological economics. Annals of the New York academy of sciences. Issue: Ecol. Econ. Rev.: 39-53.

Hafrichter R. 1993. Toxic struggles; the theory and practice of environmental justice (No. GTZ-971).

Hornsby J.S., Kuratko D.F., Zahra S.A. 2002. Middle managers' perception of the internal environment for corporate entrepreneurship: assessing a measurement scale. J. Bus. Venturin, 17: 253-273.

Hosseini S.E., Andwari A.M., Wahid M.A., Bagheri G. 2013. A review on green energy potentials in Iran. Renew. Sustain. Energ. Rev., 27: 533-545.

Hunter L.M., Strife S. 2010. Environmental Perceptions of Rural South African Residents: The Complex Nature of Environmental Concern. Soc. Natur. Res., 23: 525-541.

Iizuka M. 2000. Role of Environmental Awareness in Achieving Sustainable Development. Economic Commission for Latin America and the Caribbean, under the project 'Enhancement of Citizen's Awareness in Formulation of Pollution Control Policies in Major Latin American Cities', Environment and Human Settlements Division of ECLAC

Inagami M., Ohno R. 2009. Anisotropy of environmental perception caused by spatial changes during locomotion. J. Environ. Psychol., 30: 1-9.

Iran National climate office, 2003. Second National Communication to UNFCCC. www.Climate-chang.ir.

Iran National climate office, 2010. Second National Communication to UNFCCC. www.Climate-chang.ir.

Keary M. 2011. Message in a model: Technological optimism in climate change mitigation modeling. www.whpress.co.uk.

Kincaid, M. (2011). A Q-methodology Study: Stakeholder perspectives on the future management of Capitol Lake, Olympia, Washington. Thesis for Master of Environmental Studies Degree, Evergreen State College.

Kollmuss A., Ageyman J. 2002. Mind the Gap: why do people act environmentally and what are the barriers to proenvironmental behavior? Environ. Educ. Res., 8 (3): 239-260.

Lauber T.B., Tidball K.G. 2014. Characterizing Healthy Urban Systems: Implications for Urban Environmental Education. Cities and the Environment (CATE), 7 (2). Available at: htt://digitalcommons.lmu.edu/cate/vol7/iss2/2.

Logo E. 2013. Q-methodology method based environmental awareness measurement in transportation. Int. J. Traffic Trans. Engin., 3 (1): 45-53.

Mol P.J. 2002. Ecological Modernization and the Global Economy. Global Environ. Politics, 2 (2): 92-115.

Musich S., Hook D., Baaner S., Spooner M., Edington D.W. 2006. The Association of Corporate Work Environment Factors, Health Risks, and Medical Conditions with 
Presenteeism Among Australian Employees. Amer. J. Health Promot: November/December. 21 (2): 127-136.

Næss A. 1973. The Shallow and the Deep, Long-Range Ecology Movement. Inquiry, 16: 95-100.

Nwagbara E.N., Abia R.P., Uyang, F.A., Ejeje J.A. 2012 Poverty, Environmental Degradation and Sustainable Development: A Discourse. Global J. Human Soc. Sci., 12 (11). Online ISSN: 2249-460x \& Print ISSN: 0975-587X.

Perkins P.E. 2007. Feminist Ecological Economics and Sustainability. J. Bioecon., 9: 227-244.

Poortinga W., Steg L., Vlek C. 2004. Values, Environmental concern and environmental behavior. A study In to Household Energy Use. Environ. Behav., 36 (1): 70-93.

Ramalho-Guedes G., Luiz-Do-Carmo R. 2013. Self-interest versus collective action: understanding cross-class environmental perception, knowledge and behavior in Brazil. Papeles de poblacion, 19 (78): 223-258.

Redclift M. 1993. Sustainable Development: Needs, Values, Rights. Environ. Values, 2 (1): 3-20.

Schlosberg D. 2007. Defining Environmental Justice: Theories, Movements, and Nature. Oxford University Press, Oxford.

Smith K.R. 1993. Fuel combustion, air pollution exposure, and health: the situation in developing countries. Annu. Rev. Energ. Environ., 18 (1): 529-566.

Steelman T.A., Maguire L.A. 1999. Understanding participant perspectives: Q-methodology in national forest management J. Policy Analysis Manage., 18 (3): 361-388.
Stephenson W. 1953. The study of behavior: Q-technique and its methodology. University of Chicago Press, Chicago.

Stergiou D., Airey D. 2011. Q-methodology and tourism research. Curr. Iss. Tourism, 14, 4: 311-322.

Stern P.C. 2000. Toward a Coherent Theory of Environmentally Significant Behavior. J. Soc. Iss., 56(3). 407-424.

Swedeen P. 2006. Post-normal science in practice: A Q study of the potential for sustainable forestry in Washington State, USA. Ecol. Econ., 57, 190-208.

Utzinger J., Wyss K., Moto D.D., Tanner M., Singer B.H. 2005. Assessing health impacts of the Chad-Cameroon petroleum development and pipeline project: challenges and a way forward. Environ. impact assessment rev., 25(1), 63-93.

Venables D., Pidgeon N., Simmons P., Henwood K., Parkhill K. 2009. Living with Nuclear Power: A Q-Method Study of Local Community Perceptions. Risk Analysis, 29(8), 10891104.

Warf B. 2006. Encyclopedia of Human Geography. SAGE Publ., Inc.http://knowledge.sagepub.com/view/humangeography/ n88.xml.

Weekes V.L. 2008. Attitudes and perspectives towards water and water management in the towns of Gibsons, British Colombia. Simon Fraser University.

Zabala A. 2014. Q method: A Package to Explore Human Perspectives Using Q Methodology. The R Journal, 6/2.

Zand Hessami H., Yousefi P. 2013. Investigation of major factors influencing green purchasing behavior: Interactive approach. Eur. online J. Natur. Soc. Sci., 2 (4). 584-596. 